\title{
Version of the Reference Terminology
}

National Cancer Institute

\section{Source}

National Cancer Institute. Version of the Reference Terminology. NCI Thesaurus. Code C117376.

The version information of the terminology system that is being used. 